\title{
Lying in a native and foreign language
}

\author{
Jon Andoni Duñabeitia $\cdot$ Albert Costa
}

Published online: 4 December 2014

(C) Psychonomic Society, Inc. 2014

\begin{abstract}
This study explores the interaction between deceptive language and second language processing. One hundred participants were asked to produce veridical and false statements in either their first or second language. Pupil size, speech latencies, and utterance durations were analyzed. Results showed additive effects of statement veracity and the language in which these statements were produced. That is, false statements elicited larger pupil dilations and longer naming latencies compared with veridical statements, and statements in the foreign language elicited larger pupil dilations and longer speech durations and compared with first language. Importantly, these two effects did not interact, suggesting that the processing cost associated with deception is similar in a native and foreign language. The theoretical implications of these observations are discussed.
\end{abstract}

Keywords Deception $\cdot$ Bilingualism $\cdot$ Pupil size $\cdot$ Emotional distance

\section{Introduction}

The use of a nonnative language for social interaction in professional and nonprofessional forums is relatively common in a globalized world with more than 230 million migrants. However, despite the great deal of attention paid in recent years to specific linguistic and nonlinguistic cognitive consequences of mastering two languages (e.g., Costa \&

J. A. Duñabeitia $(\bowtie)$

Basque Center on Cognition, Brain and Language (BCBL),

Paseo Mikeletegi 69, 2, 20009 Donostia, Spain

e-mail: j.dunabeitia@bcbl.eu

A. Costa

Universidad Pompeu Fabra, Barcelona, Spain
Sebastian-Galles, 2014), further research is needed to better characterize the interactions between the cognitive stress elicited by communicating in a foreign language and social behavior. The current study focuses on the production of false statements as a window to deceptive speech. Specifically, we aim at exploring whether and how certain indices of deception are modulated by the use of a native or a foreign language while producing untruthful statements.

Sixty percent of people lie at least once during a 10-minute conversation (Feldman, Forrest, \& Happ, 2002), and despite daily occurrence of deceptive statements, the cognitive impact of lying is still poorly understood. Hence, not surprisingly, the existing evidence on the differences between producing false statements in a native vs. foreign language is restricted to a single study (Caldwell-Harris \& Aycicegi-Dinn, 2009, Experiment 2). In this experiment, participants were asked to read false and veridical statements aloud either in their native or foreign language while electrodermal activity (skin conductance responses, SCRs) was monitored. Two main results were observed. First, false statements elicited larger SCRs than veridical ones. Second, statements in a foreign language elicited larger SCRs than statements in a native language. These results were interpreted according to a "double stressor" account suggesting the presence of two cumulative factors (namely, deception and second language processing) that lead to increased cognitive stress.

The results from Caldwell-Harris and Aycicegi-Dinn (2009) suggest that deception affected participants' SCRs similarly in the two languages, given that these two main effects did not interact (i.e., the magnitude of the deception effect in the galvanic response was similar in the native and foreign language). At first glance, these results might seem surprising, because one might have expected greater deception effects in the foreign language, considering that both deception and the use of a nonnative language might increase processing demands. Hence, one could have predicted a 
significant interaction demonstrating that producing deceptive language becomes much more taxing in a foreign than in a native language.

The authors interpreted their findings in line with evidence pointing to reduced emotionality in a nonnative language (see Caldwell-Harris \& Aycicegi-Dinn, 2009, Experiment 1; see also Harris et al., 2003), which could have been partially responsible for a reduction of the psychophysical impact of deceptive speech in a foreign language. This view has been recently endorsed by studies demonstrating that decisionmaking processes sensitive to emotional reactions are modulated as a function of the language in which they are framed (native vs. foreign). Keysar, Hayakawa, and An (2012) suggested that the emotional resonance of the foreign language is lower than that of the native language, and that despite the strong emotional attachment to the native language, the emotional attachment to the nonnative language is reduced, thus yielding more rational behaviors in nonnative communicative contexts (see also Costa et al., 2014a, b). Hence, the reduced emotional resonance associated with the foreign compared with the native language could have counteracted the effect of dealing with false statements in a foreign language in the study by Caldwell-Harris and Ayçiçegi-Dinn.

In the current study, we investigated the "double stressor" account from a different perspective to clarify whether the language effects (native vs. foreign) and the effects related to the veracity of the statements (true vs. false) are fully independent (i.e., noninteracting yet additive), or whether there is a greater cost associated with the production of false statements in a foreign language. To this end, Spanish-English nonbalanced but proficient bilinguals $(n=100)$ were asked to name pictures of animals aloud. Crucially, and depending on the experimenter instructions, participants were asked either to describe the animal that they saw (true statements) or describe any of the other two animals included in the experiment (false statements). We measured different variables that have been shown to be sensitive to the processing costs associated with foreign language processing and with deception: pupil size and verbal responses. The main question addressed in the study refers to whether deceiving in a foreign language incurs a larger (or smaller) cost than deceiving in a native language.

Pupils dilate as a response to various forms of cognitive stress, such as actions that involve high memory load, emotional reactions, or enhanced cognitive difficulty (e.g., Beatty, 1982; Kahneman \& Beatty, 1966; see Goldinger \& Papesh, 2012, for review). Lying is one of these cognitively demanding scenarios in which pupils tend to dilate. Since the first observations by Berrien \& Huntington (1942), several studies have repeatedly reported an increase in pupil size associated with deception (see, among many others, Dionisio et al., 2001; Lubow \& Fein, 1996). In a parallel manner, pupil size changes also are sensitive to the language in which the individual is speaking. In fact, nonnative linguistic contexts elicit greater pupil dilation than native language contexts. For example, Hyönä, Tommola, and Alaja (1995) observed that participants' pupils were larger when participants were asked to repeat words in their nonnative language as compared with their native one (see also Schmidtke, 2014).

Different measures of speech latencies have been used to index differences in native versus foreign language processing, and between false and true statements. For example, vocal pitch changes and high fundamental frequency $\left(\mathrm{F}_{0}\right)$ have been considered relatively good markers of deceptive speech (e.g., Ecoff, Ekman, Mage, \& Frank, 2000; Streeter et al., 1977; but see Spence, Villar, \& Arciuli, 2012). More importantly for our purposes here, speech latency measures also are sensitive to deception. Vrij, Edward, Roberts, and Bull (2000) showed that response latencies (measured by voice onset times) are longer in deceptive than true statements (see also Spence et al., 2012; Sporer \& Schwandt, 2006). Regarding language context, foreign language production elicits longer naming latencies and utterance durations than the native one does (BlumKulka \& Olshtain, 1986; Ivanova \& Costa, 2008; Sadat, Martin, Alario, \& Costa, 2012; Strijkers et al. 2013 for a review). Although the precise origin of this effect is still under debate, there is agreement in assuming that it reflects some form of cognitive load associated with foreign language processing.

In summary, pupil size, voice onset times, and utterance durations are reliable measures of the main independent variables manipulated in our study: the veracity of the statements (true vs. false) and the language in which the statements are produced (native vs. foreign). As a consequence, they provide a useful proxy to assess how these two variables may potentially interact with each other. Considering that foreign language processing and deceptive statements affect verbal and ocular responses as a result of cognitive stress, one could tentatively predict that the two effects would interact, leading to a larger effect of deception in a foreign language. However, one could also put forward an alternative outcome grounded in the lower emotional resonance associated with the foreign language. Namely, similar effects of producing false compared to true statements in both languages, or in the extreme case, smaller effects of deception in the foreign than in the native language.

\section{Methods}

Participants

One hundred neurologically intact Spanish native speakers with normal or corrected-to-normal vision (67 females; mean age 22 years; age range 18-35) took part in this experiment. All participants had English as a nonnative language 
(maximum age of acquisition of English was 13 years; mean = 6.79). English proficiency was evaluated by gathering subjective and objective measures. After completing a linguistic questionnaire, participants performed a picture-naming test (comprised of 77 drawings) in their two languages. While, as expected, performance was better in Spanish than in English, participants showed relatively good performance in the foreign language (Table 1). Furthermore, a SpanishEnglish bilingual individually interviewed all participants for 5 minutes, rating their communicative skills in each language on a 1-to-5 scale. Participants were randomly assigned to the native or foreign language condition (resulting in two groups matched for age and language skills). The experiment was approved by the BCBL Ethics Committee.

\section{Materials and procedure}

Each participant completed the experiment in the language assigned (Spanish or English). Participants were presented with 60 trials consisting of the initial presentation of a fixation cross (that also served to perform inter-trial drift corrections compensating for minimal head movements), followed by the presentation of the target picture for $2000 \mathrm{~ms}$. Three target pictures were used during the experiment: a white sheep with four legs, a brown spider with eight legs, and a yellow bird with two legs. Participants were informed that the experiment contained two types of trials. In true statement trials (30 trials), participants had to provide the correct definition of the animal displayed. In contrast, in false statement trials (30 trials), participants had to lie, providing the definition of any of the other two animals, instead of the definition of the displayed

Table 1 Characteristics of the participants in each group (native language and foreign language). Standard deviations are provided in parentheses.

\begin{tabular}{|c|c|c|c|}
\hline & All participants & $\begin{array}{l}\text { Native } \\
\text { language }\end{array}$ & $\begin{array}{l}\text { Foreign } \\
\text { language }\end{array}$ \\
\hline Age (yr) & $22.16(2.80)$ & $22.20(2.84)$ & $22.12(2.77)$ \\
\hline Number of females & 67 & 30 & 37 \\
\hline \multicolumn{4}{|c|}{ Correctly named pictures (out of 77)*: } \\
\hline Spanish & $76.44(0.87)$ & $76.40(0.90)$ & $76.48(0.84)$ \\
\hline English & $48.38(8.33)$ & $48.44(8.45)$ & $48.32(8.30)$ \\
\hline \multicolumn{4}{|c|}{ Age of acquisition (yr): } \\
\hline Spanish & $0.35(1.16)$ & $0.46(1.28)$ & $0.24(1.02)$ \\
\hline English & $6.79(2.26)$ & $6.56(1.89)$ & $7.02(2.58)$ \\
\hline \multicolumn{4}{|c|}{ Score in individual interview (1-to-5 scale): } \\
\hline Spanish & $5.00(0)$ & $5.00(0)$ & $5.00(0)$ \\
\hline English & $3.23(0.63)$ & $3.22(0.62)$ & $3.24(0.66)$ \\
\hline
\end{tabular}

* Score corresponds to the number of correctly named drawings in the bilingual picture-naming test used to assess participants' vocabulary in each language (see Gollan et al., 2012) animal. Participants were asked to limit their verbal responses to the following linguistic structures:

English: "I see a [color] [animal] with [number of legs] legs" (e.g., "I see a white sheep with four legs").

Spanish: "Veo un/a [animal] [color] con [number of legs]

patas" (e.g., "Veo una oveja blanca con cuatro patas").

Trial status (false or true statement) was indicated 2 seconds after the onset of the target picture by a color cue (green or red) presented in the upper part of the screen. The cue and the target picture then remained on the screen for 5 seconds. Participants were instructed to respond as soon as possible after cue presentation, and they were encouraged to cover up any specific marker that could make false statements clear to the experimenter. To increase participants' involvement, they were told that all their statements would be subsequently judged for veracity by a native Spanish-English bilingual, and that they would receive additional compensation if the judge could not efficiently determine the statements' veracity.

After a familiarization phase, the experiment proper was administered. The three target pictures were presented 20 times each (60 trials), with a similar number of true and false statement trials per animal (10 each). Trial presentation was randomized across participants.

Materials were presented on a screen linked to a PC, using Experiment Builder software that also served to collect the verbal responses and to monitor the right pupil of the participants. Eye movements were recorded at a rate of $500 \mathrm{~Hz}$ using an SR Research EyeLink-II eye-tracker and verbal responses were recorded with a Sennheisser PC151 device.

\section{Results}

Prior to analyzing the results, a data-cleaning process was carried out. Trials in which participants did not follow the instructions or gave incomplete responses were discarded from the analysis (only $2.10 \%$ of the data). The voice onset latencies and the duration (both in $\mathrm{ms}$ ) of the accurate responses were then calculated individually. Participants' pupil size increment or decrement (in percentage of change) during the whole 5-seconds period of the accurate trials were computed with respect to a baseline measure, consisting of the size of the pupil of each participant in each trial during the $2 \mathrm{sec}$ onds between the initial presentation of the target picture and the presentation of the color cue. Importantly, pupil sizes during the baseline period did not differ across groups $(p>$ 0.96). For each of the three dependent measures (percentage of pupil size change, voice onset latency and utterance duration), trials in which the values exceeded more than \pm 2.5 standard deviations from the mean for each participant in each 
condition were considered outliers and were subsequently discarded from the analysis (percentage of pupil change: $1.63 \%$ of the trials; voice onset latency: $1.36 \%$ of the trials; utterance duration: $2.71 \%$ of the trials). The remaining data were analyzed in a series of ANOVAs following a $2 \times 2$ Language (Native|Foreign) $\times$ Statement $($ True $\mid$ False) design . Means for each measure per condition are presented in Table 2

\section{Percentage of pupil change}

Participants' pupil size increased after the statement cue was presented as compared with the baseline $(p<$ 0.001 ), with the only exception of the true statement trials in the foreign language, which did not show significant pupil dilation effects $(p=0.14)$. The main effect of Language was significant, showing that pupils dilated more in the foreign than in the native language condition $\left[\mathrm{F}(1,98)=12.97, p<0.001\right.$, partial $\eta^{2}=0.12$, $1-\beta=0.95]$. Similarly, false statements elicited larger pupil dilations than true statements, as shown by the main effect of Statement $(2.67 \%$ difference $)[\mathrm{F}(1,98)=$ 112.66, $p<0.001$, partial $\left.\eta^{2}=0.53,1-\beta=1\right]$. Crucially, the interaction between these two factors was not significant $\left[\mathrm{F}<1, p>0.92\right.$, partial $\left.\eta^{2}<0.01,1-\beta<0.06\right]$, showing that the effect of deception was highly similar in the native and foreign language $(2.68 \%$ and $2.64 \%$ increase, respectively).

We also explored the time-course of pupil dilation across the experimental trial to achieve a more detailed picture of how false and true statements affected pupil dilation. The pupil-tracking period of 5 seconds was divided in 5 different bins of 1 second each, and parallel ANOVAs were run for each slot. As shown in Fig. 1, the time course of deception was very similar in the two languages. The Statement effect was significant in all the bins [all $\mathrm{F}>13.92, p<0.001$, partial $\eta^{2}>0.11$, $1-\beta>0.95]$, showing the maximum effect between 2000 and $3000 \mathrm{~ms}$. The effect of Language was small, yet significant, in the first bin $\left[\mathrm{F}(1,98)=3.78, p=0.05\right.$, partial $\eta^{2}=0.04,1-\beta=$ 0.49 ], remained significant in the following 3 epochs $[\mathrm{F}>$ $6.04, p<0.01$, partial $\left.\eta^{2}>0.05,1-\beta>0.68\right]$ and was negligible in the last time window $\left[\mathrm{F}<1, p>41\right.$, partial $\eta^{2}=0.01,1-\beta=$ $0.13]$. Importantly, the interaction between these two factors was not significant in any bin $[p>0.11]^{1}$.

\section{Voice onset latency}

Participants' onset naming latencies were significantly longer in false than in true statements (119-ms difference; Table 1;

\footnotetext{
${ }^{1}$ On average, participants had completed their verbal productions before the last analyzed epoch. Thus, we interpret the lack of a Language effect in this last time window as an indication of task completion.
}

Table 2 Mean percentage of pupil change, mean voice onset latency (in ms) and mean utterance duration (in ms) in the True and False Statement conditions together with the deception effect (i.e., False True) in each language group. Standard deviations are provided in parentheses.

\begin{tabular}{llll}
\hline & $\begin{array}{l}\text { False } \\
\text { statements }\end{array}$ & $\begin{array}{l}\text { True } \\
\text { statements }\end{array}$ & Effect \\
\hline All participants & & & \\
$\quad \begin{array}{lll}\text { Percentage of pupil change } \\
\text { Voice onset latency (ms) }\end{array}$ & $5.10 \%(4.82)$ & $2.43 \%(4.56)$ & $2.67 \%$ \\
Utterance duration (ms) & $2302(397)$ & $848(163)$ & 119 \\
Native language & & & -2 \\
Percentage of pupil change & $3.57 \%(389)$ & \\
Voice onset latency (ms) & $975(224)$ & $865(182)$ & 110 \\
$\quad$ Utterance duration (ms) & $2133(341)$ & $2144(345)$ & -11 \\
Foreign language & & & \\
Percentage of pupil change & $6.62 \%(5.01)$ & $3.98 \%(4.38)$ & $2.64 \%$ \\
Voice onset latency (ms) & $959(200)$ & $832(142)$ & 127 \\
Utterance duration (ms) & $2472(379)$ & $2464(366)$ & 8 \\
\hline
\end{tabular}

Statement $\left[\mathrm{F}(1,98)=133.56, p<0.001\right.$, partial $\eta^{2}=0.58,1-\beta=$ 1]. The main effect of Language was not significant, nor was the interaction between the two factors $[\mathrm{F}<1, p>0.42$, partial $\left.\eta^{2}<0.02,1-\beta<0.13\right]$.

Utterance duration

Utterances' durations were longer in the foreign than in the native language (Language $[\mathrm{F}(1,98)=21.44, p<0.001$, partial $\left.\eta^{2}=0.18,1-\beta=1\right]$. The main effect of Statement was not significant, nor was the interaction between the two factors either $\left[\mathrm{F}<1.5, p>0.22\right.$, partial $\left.\eta^{2}<0.02,1-\beta<0.24\right]$.

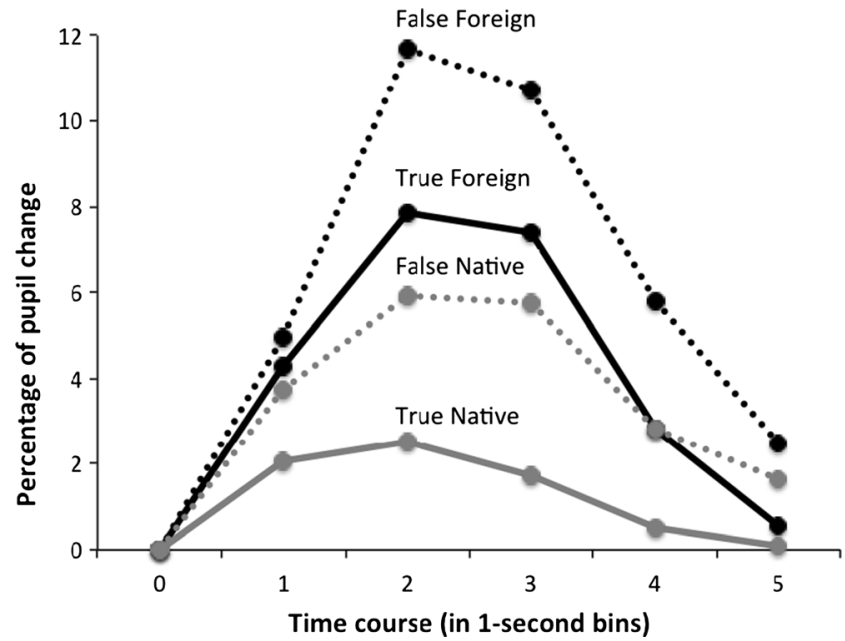

Fig. 1 Time course of the percentage of pupil change (as compared to the baseline) in 5 consecutive 1-second time windows in the True and False Statement conditions (straight and dotted lines, respectively) for the Native (grey lines) and Foreign language (black lines) 


\section{Discussion}

The current study was designed to explore the interaction between the production of false statements and the language in which they are produced (native vs. foreign). Three main findings were observed:

i) Pupil dilation was greater and utterance durations were longer when speaking in a foreign than in a native language;

ii) Pupil dilation was greater and voice onset latencies were longer when producing false statements compared with true statements;

iii) The magnitude of the effect of producing false statements for all these variables was comparable in the two languages.

Together these results suggest that the processing costs associated with producing deceptive (false) statements are independent of the $\operatorname{cost}(\mathrm{s})$ associated with speaking in a foreign language. In other words, whatever burden the production of false statements incurs, it does so to the same extent regardless of the language used and regardless of the participants' proficiency in that language, at least for nonbalanced sequential bilinguals.

Pupillometric responses showed increased dilation in false statement trials as well as when speaking in a foreign language (in line with the SCRs reported by Caldwell-Harris \& Aycicegi-Dinn, 2009). However, our results further qualify their "double stressor" account by demonstrating that the cognitive costs derived from deception and foreign language production occur at different, independent levels of processing. The verbal measures collected in the current study (voice onset latency and utterance duration) are related to two different stages of processing (preverbal and verbal, respectively). Considering that only voice onsets were sensitive to the statement manipulation, we suggest that the cognitive cost associated with the production of false statements occurs mainly at the preverbal stage, when speakers need to choose the conceptual information that will be conveyed. This preverbal stage can be argued to be more taxing when producing false statements than when telling the truth because the speaker needs to monitor the preverbal message to a greater extent, among other factors. Lying about something that has been experienced necessarily requires a prominent response (the truthful statement) to be inhibited in order to produce an untruthful statement. Once this step is achieved, lexicalization and verbalization of the intended message can proceed with relative independence of the type of statement, while still being highly sensitive to the language in which the utterance is produced. While the cost associated with deception mostly occurred at the conceptualization process, the cost associated with producing speech in a foreign language mostly occurred at later stages during lexical access and phonological retrieval, suggesting an additive-yet-independent conception of the effects. This temporal dissociation allows for a clear-cut distinction between the effects of deception occurring during conceptualization (i.e., during the creation temporary representations in working memory), and the effects of target language fluency occurring during formulation and articulation (see Levelt, 1989).

Admittedly, while the current study tried to emulate an ecological scenario to seek differences between lying in a native and foreign language, there are several differences between participants' production of false statements and actual deceptive speech. Given the reduced number of items used in the current experiment and the redundant nature of the utterances, one could suggest that rather than tapping into deception per se, this study mainly focused on participants' skills associated with the inhibition of prominent responses (i.e., inhibiting the true statement in trials requiring a false statement). Although it is difficult to fully reject this possibility, in order to address it, we conducted an analysis exploring the change of the effects over the course of the experiment. If this experiment mostly assesses participants' inhibitory skills, the observed effects may be sensitive to training effects across the experimental session (see Chen, Tang, \& Chen, 2013, for review). To that effect, we ran an ANOVA on the percentages of pupil change across conditions (Statement and Language factors), including a temporal dimension associated with trial order (Block factor: first vs. second half of the experiment). Results showed a main effect of Language $[\mathrm{F}(1,98)=14.15, p<0.001]$ and of Statement $[\mathrm{F}(1,98)=75.02, p<0.001]$, but neither the effect of Block nor the interactions between factors reached significance $[p=0.13]$. Hence, these results help us confidently reject an interpretation of these data on the mere basis of response inhibition effects, and suggest that the mechanisms tested in this study are relatively strategy-free and automatic.

Critically, the first-acting cost associated with producing false statements did not snowball into the later-acting cost associated with foreign language speech production (as could be interpreted by the "double stressor" account by CaldwellHarris \& Aycicegi-Dinn, 2009), suggesting the presence of a compensatory mechanism that indeed reduces the burden of lying in a foreign language. A growing number of studies suggest that second language processing may dampen the emotional resonance of the message, prompting some form of psychological distance in foreign language contexts (see Harris, 2004; Harris, Aycicegi, \& Berko Gleason, 2003; Pavlenko, 2008, 2012). Admittedly, the precise origin of this reduction in emotional reactivity is not yet fully understood, but it has quite pervasive effects, extending not only to language processing itself but also to decision-making processes (see Keysar, Hayakawa, \& An, 2012; Costa et al., 2014a, b). Hence, it could be hypothesized that when asked to produce false statements in a foreign language, participants can partially 
distance themselves from the anxiety associated with lying. This psychological distance may reduce the burden associated with lying, therefore acting as a compensatory factor when producing deceptive utterances in a second language.

To conclude, the present study shows that, despite the cognitive cost associated with speaking in a nonnative language, the additional cognitive burden posed by lying is independent of the language in which the false statements are produced. We suggest that is partially due to the aid of the emotional distance that nonnative speakers have with regard to the foreign language. This is certainly a tentative hypothesis deserving further research.

Acknowledgments This research has been partially funded by grants PSI2012-32123 from the Spanish Government, ERC-AdG-295362 grant from the European Research Council, and by the AThEME project funded by the European Union Seventh Framework Programme (grant number 613465)

\section{References}

Beatty, J. (1982). Task-evoked pupillary responses, processing load, and the structure of processing resources. Psychological Bulletin, 91(2), 276-292.

Berrien, F. K., \& Huntington, G. H. (1942). An exploratory study of pupillary responses during deception. Journal of Experimental Psychology, 32, 443-449.

Blum-Kulka, S., \& Olshtain, E. (1986). Too many words: Length of utterance and pragmatic failure. Studies in Second Language Acquisition, 8, 47-61.

Caldwell-Harris, C. L., \& Aycicegi-Dinn, A. (2009). Emotion and lying in a non-native language. International Journal of Psychophysiology, 71, 193-204.

Chen, A., Tang, D., \& Chen, X. (2013). Training reveals the sources of stroop and flanker interference effects. PloS One, 8(10), e76580.

Costa, A., \& Sebastian-Galles, N. (2014). How does the bilingual experience sculpt the brain? Nature Reviews Neuroscience, 15, 336-345.

Costa, A., Foucart, A., Arnon, I., Aparici, M., \& Apesteguia, J. (2014a). "Piensa" twice: On the foreign-language effect in decision making. Cognition, 130(2), 236-354.

Costa, A., Foucart, A., Hayakawa, S., Aparici, M., Apestguia, J., Heafner, J., \& Keysar, B. (2014b). Your morals depend on language. PloS One, 9(4), e94842.

Dionisio, D. P., Granholm, E., Hillix, W. A., \& Perrine, W. F. (2001). Differentiation of deception using pupillary responses as an index of cognitive processing. Psychophysiology, 38(2), 205-211.

Ecoff, N. L., Ekman, P., Mage, J. J., \& Frank, M. G. (2000). Lie detection and language loss. Nature, 405, 139.

Feldman, R. S., Forrest, J. A., \& Happ, B. R. (2002). Self-presentation and verbal deception: Do self-presenters lie more? Basic and Applied Social Psychology, 24, 163-170.
Goldinger, S. D., \& Papesh, M. H. (2012). Pupil dilation reflects the creation and retrieval of memories. Current Directions in Psychological Science, 21(2), 90-95.

Gollan, T. H., Weissberger, G. H., Runnqvist, E., Montoya, R. I., \& Cera, C. M. (2012). Self-ratings of spoken language dominance: A Multilingual Naming Test (MINT) and preliminary norms for young and aging Spanish-English bilinguals. Bilingualism: Language and Cognition, 15(3), 594-615.

Harris, C. L. (2004). Bilingual speakers in the lab: Psychophysiological measures of emotional reactivity. Journal of Multilingual and Multicultural Development, 2, 223-247.

Harris, C. L., Aycicegi, A., \& Berko Gleason, J. (2003). Taboo words and reprimands elicit greater autonomic reactivity in a first than in a second language. Applied Psycholinguistics, 24, 561-578.

Hyönä, J., Tommola, J., \& Alaja, A. M. (1995). Pupil dilation as a measure of processing load in simultaneous interpreting and other language tasks. Quarterly Journal of Experimental Psychology, $48 \mathrm{~A}, 598-612$

Ivanova, I., \& Costa, A. (2008). Does bilingualism hamper lexical access in speech production? Acta Psychologica, 127, 277-288.

Kahneman, D., \& Beatty, J. (1966). Pupil diameter and load on memory. Science, 154(3756), 1583-1585.

Keysar, B., Hayakawa, S., \& An, S. G. (2012). The foreign language effect: Thinking in a foreign tongue reduces decision biases. Psychological Science, 23, 661-668.

Levelt, W. J. M. (1989). Speaking: From intention to articulation. Cambridge, MA: The MIT Press.

Lubow, R. E., \& Fein, O. (1996). Pupillary size in response to a visual guilty knowledge test: New technique for the detection of deception. Journal of Experimental Psychology: Applied, 2, $164-177$

Pavlenko, A. (2008). Emotion and emotion-laden words in the bilingual lexicon. Keynote article. Bilingualism: Language and Cognition, 11(2), 147-164.

Pavlenko, A. (2012). Affective processing in bilingual speakers: Disembodied cognition? International Journal of Psychology, 47(6), 405-428.

Sadat, J., Martin, C. D., Alario, F. X., \& Costa, A. (2012). Characterizing the bilingual disadvantage in noun phrase production. Journal of Psycholinguistic Research, 41(3), 159-179.

Schmidtke, J. (2014). Second language experience modulates word retrieval effort: Evidence from pupillometry. Frontiers in Psychology, 5, 137.

Spence, K., Villar, G., \& Arciuli, J. (2012). Markers of deception in Italian speech. Frontiers in Psychology, 3, 453.

Sporer, S., \& Schwandt, B. (2006). Paraverbal indicators of deception: A meta-analytic synthesis. Applied Cognitive Psychology, 20, 421466.

Streeter, L. A., Krauss, R. M., Geller, V., Olson, C. T., \& Apple, W. (1977). Pitch changes during attempted deception. Journal of Personality and Social Psychology, 35, 345-350.

Strijkers, K., Baus, C., Runnqvist, E., Fitzpatrick, I., \& Costa, A. (2013). The temporal dynamics of first versus second language speech production. Brain and Language, 127(1), 6-11.

Vrij, A., Edward, K., Roberts, K. P., \& Bull, R. (2000). Detecting deceit via analysis of verbal and nonverbal behavior. Journal of Nonverbal Behavior, 24(4), 239-263. 